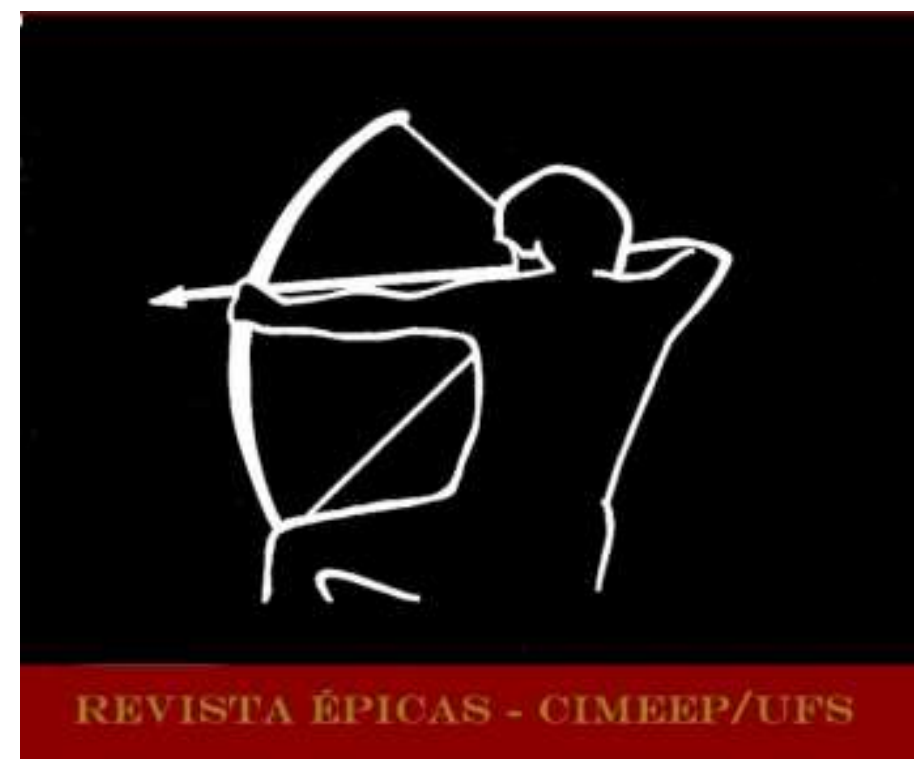

MACIEL, Luciana Novais; SILVA, Tatiana Cíntia. Algumas incursões entre o histórico e o maravilhoso em A lágrima de um caeté. In: Revista Épicas. Ano 5, n. 9, Jun 2021, p. 71-83. ISSN 2527-080-X. DOI: DOI: http://dx.doi.org/10.47044/2527-080X.2021v97183

\title{
ALGUMAS INCURSÕES ENTRE O HISTÓRICO E O MARAVILHOSO EM A LÁGRIMA DE UM CAETÉ
}

\section{SOME INCURSIONS BETWEEN HISTORICAL AND WONDERFUL IN A LÁGRIMA DE UM CAETÉ}

\author{
Luciana Novais Maciel ${ }^{1}$ \\ (PPGL/UFS) \\ Tatiana Cíntia da Silva² \\ (PPGL/UFS)
}

RESUMO: Neste artigo pretendemos compreender certos elementos literários e históricos que permeiam a obra A Lágrima de Um Caeté (1849), de Nísia Floresta e, para tal intento, dialogaremos com Candido (1985), Margutti (2019), Vasconcelos e Ramalho (2007), Duarte (1999) e Quijano (2005). Nosso objetivo maior é trilhar alguns caminhos que apontam como o livro tem tanto traços de um Indianismo crítico quanto de elementos que remontam aos textos épicos, por recuperar o heroísmo coletivo, o plano histórico e o maravilhoso, mas em nenhum momento colocaremos o lirismo narrativo da autora em um padrão prefixado e/ou cristalizado, pois isso não condiz com os rumos do texto que nos debruçaremos. Outrossim, também tocaremos na questão de decolonialidade, visto que adentraremos em um ambiente de aculturação e destruição da cultura indígena e o texto em estudo acaba por se tornar uma poesia de resistência.

Palavras-chave: Indianismo crítico; plano maravilhoso; plano histórico.

\footnotetext{
1 Doutoranda no Programa de Pós-graduação em Letras (UFS), Mestre em Literatura Brasileira (UFAL), Professora da Faculdade Pio Décimo, Orientadora e bolsista do Programa de Residência Pedagógica 2020-2022 (CAPES). E-mail: luemeester@gmail.com ,Orcid: https://orcid.org/0000-0003-1053-4316

2 Doutoranda no Programa de Pós-graduação em Letras (UFS), Mestra em Literatura pela mesma instituição, Professora da Faculdade Pio Décimo. E-mail: tatiana.cintia.ts@gmail.com, Orcid: https://orcid.org/0000-0002-1987-0415
} 
ABSTRACT: In this article, we intend to understand certain literary and historical elements that permeate the work A Lágrima de Um Caeté (1849), by Nísia Floresta, and, for this purpose, we will dialogue with Candido (1985), Margutti (2019), Vasconcelos and Ramalho (2007), Duarte (1999) and Quijano (2005). Our main objective is to follow some paths that show how the book has both traces of a critical Indianism and elements that go back to epic texts for recovering the collective heroism, the historical and the wonderful plan, but at no time will we put the author's narrative lyricism in a prefixed and/or crystallized pattern, as this does not match the directions of the text that we will look at. Furthermore, we will also touch on the issue of decoloniality, as we will enter an environment of acculturation and destruction of indigenous culture and the text under study ends up becoming a poetry of resistance.

Keywords: Critical Indianism; wonderful plan; historical plan

\section{Introdução}

Neste artigo buscaremos dialogar com a epopeia A lágrima de um Caeté - obra escrita em 1849 por Nísia Floresta - entrelaçando os aspectos históricos, que marcam todo o texto, cuja concepção fundou-se em fatos ocorridos à época, como a Revolução Praieira em Pernambuco, com os aspectos do maravilhoso, os quais percorrem o imaginário do índio Caeté em suas reflexões, seu desejo de vingança e a decepção com os seus pares.

Nísia Floresta é potiguar, mas, no momento da insurreição, sentia-se totalmente pernambucana, tinha conhecimento das causas políticas e econômicas do país, compartilhava com os maiores líderes da rebelião, como Nunes Machado, os ideais de liberdade até então dominada e limitada pelos portugueses, conforme apontaremos adiante. Aliás, como afirma Duarte, "em sua militância literária, a autora mostrar-se-á sempre coerente com os princípios liberais, assumindo o discurso progressista em defesa do oprimido, seja ele o índio, o negro ou a mulher" (DUARTE, 1999, p. 4).

É válido ressaltar que, em relação à obra em foco, utilizaremos a edição virtual de 2015, uma proposta especial organizada pelo então professor Waldemar Valença Pereira, da rede pública de ensino de Sergipe. O professor organizou um projeto de poesia ilustrada juntamente com os alunos do 9o ano do ensino fundamental, sob a orientação da professora-doutora Christina Bielinski Ramalho, da Universidade Federal de Sergipe, por ocasião do Mestrado Profissional em Letras (PROFLETRAS). O projeto final conta com as ilustrações dos alunos que fizeram após a leitura, interpretação e estudo sobre a epopeia.

O texto de Nísia Floresta não segue a herança clássica das epopeias, mas encontramos alguns elementos formais que foram retirados dessa tradição e que destacaremos posteriormente. Embora não seja um texto de porte épico clássico, é longo o suficiente, pois possui 712 versos que apresentam a narrativa de um drama histórico com marcas de crueldade humana. No mais, a autora tematiza a derrota do indígena ligada ao fracasso também dos liberais pernambucanos com a morte de Nunes Machado, assumindo, por isso, o tom de elegia anunciado no título (DUARTE, 1999). Sendo assim, 
organizamos esta discussão em dois momentos: considerações históricas na épica de Nísia Floresta e algumas construções no âmbito do literário.

\section{Considerações históricas na epopeia de Nísia Floresta}

Em A lágrima de um caeté (1849), observamos que a autora buscava defender os indígenas que se encontravam em degradante situação. A construção literária de Nísia Floresta se diferencia dos demais romancistas da época, os quais, em geral, enxergavam os indígenas como seres exóticos, selvagens, fortes que instigavam a curiosidades de muitos estrangeiros. A autora, no entanto, os vê como vítimas da opressão colonizadora europeia, visto que foram exterminados a partir da ambição e do desejo de domínio. Assim, a partir do poema, é possível atualizar as problemáticas sociais trazidas à luz por Floresta, tendo como base teórica, para a leitura que propomos, a colonialidade do poder e o movimento de decolonização eurocêntrica.

Antes de transpormos a problemática para a atualidade, faz-se necessária uma retomada dos acontecimentos históricos na sociedade pernambucana e brasileira no período do Segundo Reinado (1840 a 1889), quando D. Pedro II - ainda adolescente - estabeleceu o Código de processo Criminal e a reforma da guarda nacional, quando o Exército seria o encarregado de garantir as fronteiras do país (CARVALHO, 2003). Nesse contexto, a insatisfação da sociedade e a divisão entre conservadorismo e liberais no tocante à monopolização das terras pelos portugueses foram o estopim para a Revolução Praieira ou Revolta dos Rebeldes em Pernambuco.

Para muitos historiadores, os conflitos, que tiveram início em novembro de 1848 e se estenderam até fevereiro de 1849 , foram provocados quando as tropas dos conservadores tentavam desarmar os donos de engenho. Em meio aos conflitos armados, destacava-se um grande orador, o deputado Joaquim Nunes Machado, que foi atingido em um desses conflitos, fato que, quando ocorreu, foi considerado como marco da derrota dos praieiros, que teve um enfraquecimento nas batalhas, principalmente nas intelectuais (CARVALHO, 2003).

Segundo o historiador Marcus de Carvalho:

\footnotetext{
A Insurreição Praieira bem que poderia ter sido desejada pelo partido Conservador, pois nada poderia beneficiá-los mais do que o 1848 pernambucano. De fato, a Praieira causou um estrago ainda maior do que o movimento de 1842 em Minas e São Paulo, reverberando até a corte, selando o futuro do partido Liberal que declinaria em todo o país (CARVALHO, 2003, p. 116).
}

É certo que, após a morte de Nunes Machado, praticamente houve um silenciamento das revoltas, e a Praieira foi a última com caráter mais liberal. Entretanto, as motivações socialistas e a possibilidade de poder conquistar os direitos assegurados à população perduraram por muitos anos, até o possível retorno dos liberais ao poder no Parlamento, o que veio ocorrer somente em 1864. 
Como memória dos fatos ocorridos na Revolução da Praieira, a autora Nísia Floresta quis deixar registrada, em forma de poesia, a marca da luta daquele povo. Inclusive a própria autora sofreu censura com o seu texto por retratar a revolta e trazer uma singela homenagem a Nunes Machado e aos indígenas que vivenciaram todo o processo de revolta.

Constância Lima Duarte (1999), ao pesquisar a obra de Nísia Floresta, descobriu algumas situações problemáticas vivenciadas pela escritora em relação à epopeia na qual se registra o sentimento da Revolução Praieira e do seu povo. O longo poema foi escrito logo após o falecimento de Nunes Machado, e, no mesmo mês, a autora já o queria impresso. Porém, alguns empecilhos impuseram dificuldades, em especial a censura, uma vez que a autora trazia à cena a revolta que estarreceu o país como um todo (DUARTE, 1999).

No texto, logo de início, encontramos o "Avant-Propos", uma apresentação em formato de contestação, de denúncia:

O infeliz Caeté, apesar de ter chegado a esta corte no mês de fevereiro logo depois da revolta dos Rebeldes em Pernambuco, é somente agora que Ihe permitiram aparecer, e isto depois de o terem feito passar por mil torturas inquisitoriais!... Graças à benfazeja mão que o fez renascer, qual Fênix, das cinzas a que o haviam ou queriam reduzir! $(2015$, p. 6)

A referência acerca das "torturas inquisitoriais" traz à tona a censura imposta à época pelo imperador. A autora apresenta críticas aos portugueses, à violenta e sangrenta revolução, à dizimação dos indígenas e das florestas. De acordo com Duarte "se não chegam a comprometer a compreensão do texto como um todo, em vários momentos estas linhas deixam em suspenso uma ideia ou uma fala, cuja continuidade não encontramos" (DUARTE, 1999, p. 3). Por diversos momentos, há lacunas no texto que deixam em suspenso a conclusão dos pensamentos. Às vezes, por exemplo, o assunto da revolta dos rebeldes surge inesperadamente, quebrando a sequenciação do texto, ou seja, vê-se nesses trechos a possibilidade de o poema ter sido adulterado pela censura dos conservadores.

O posicionamento adotado por Nísia Floresta na elaboração da epopeia é contrário ao percurso adotado pelos escritores indianistas, pois a autora posiciona o indígena como um derrotado frente às inúmeras perdas diante do poder do homem branco, europeu e dominador. Diferentemente da postura indianista, em que o suporte ideológico é o da teoria do bom selvagem, do ser domesticado e romantizado, a autora transpõe esse movimento e nos apresenta uma proposta crítica, de um realismo social. Corroborando, assim, com Duarte:

Se o poema denuncia a situação real de vida do indígena e trata da derrota liberal dos praieiros, ele está, por conseguinte, se afastando do exotismo romântico e se aproximando de uma concepção realista fundada na crítica social. Desta forma, a construção indigenista pode mesmo ser considerada como uma dramatização do herói dividido, deslocado, sem lugar (DUARTE, 1999, p. 12). 
Na perspectiva apresentada, podemos dialogar com Quijano (2005) ao discutir as condições do processo de colonialidade do poder exercido sobre os nativos, o que provocou não só a dominação do território, mas também o conflito identitário. O crítico nos coloca diante da história das Américas, permitindo refletir sobre o apagamento de diversos povos e suas culturas, daqueles que lutaram contra a hegemonia do poder colonial eurocêntrico. É o que se vê no seguinte trecho do poema:

\author{
Não the cingia a fronte um diadema, \\ Insígnia de opressor da humanidade... \\ Armas não empunhava, que os tiranos \\ Inventaram cruéis, e sob as quais \\ Sucumbe o rijo peito, vence o inerte, \\ Mata do fraco a bala o corajoso, \\ Mas deste ao pulso forte aquele foge... \\ (FLORESTA, 2015, p. 7)
}

$\mathrm{Na}$ desigualdade de forças, observamos uma descrição do Caeté sobre o seu dominador, que estabelecem os elementos que o impedem de proteger o seu povo, a sua terra: os interesses exploratórios e de dominação do colonizador. $\mathrm{O}$ indígena descrito por Nísia Floresta é o que enfrenta a crueldade do branco, é o que está diante das armas do tirano, do opressor da humanidade.

\author{
E dá que de vulcão medonha horrível \\ A cratera se expanda abrasadora \\ Para o povo engolir, que a nós de povo \\ O nome até roubou-nos... extinguiu! \\ Estas vozes soltando angustiados \\ Emudece o Caeté... Quedo ficou, \\ Com os olhos no céu, dele esperando \\ A tardia, porém certa justiça! \\ (FLORESTA, 2015, p. 21)
}

O Caeté reflete sobre a crueldade cometida contra Nunes Machado, "o Gênio do Brasil", o qual liderava as propostas liberais em defesa da pátria e do índio, e alvejado por arma dos seus semelhantes, brancos. Na reflexão proposta, verificamos mais um momento em que a autora questiona as relações de poder e as consequências disso, o conflito identitário. Conforme afirma Quijano, "na América Latina, a ideia de raça foi uma maneira de outorgar legitimamente as relações de dominação impostas pela conquista" (QUIJANO, 2005, p. 118). Tal dominação se reflete em "o nome até roubou-nos... extinguiu!", sendo imposta uma nova identidade ao indígena e ao negro, a saber, uma identidade racial, colonial e negativa.

O emudecimento das vozes dos Caetés referenciado pela autora, condição registrada na epopeia, marca a transposição de barreiras que Nísia Floresta imputava naquele momento, eternizando-a no texto literário, por anunciar, naquele momento, o caminho para a decolonização diante das consequências do legado autoritário e dominador dos europeus. 
A perspectiva do poder eurocêntrico, que tinha total domínio do capital nas Américas, através da exploração do trabalho dos nativos e da usurpação da terra, se presentifica na fala do Caeté:

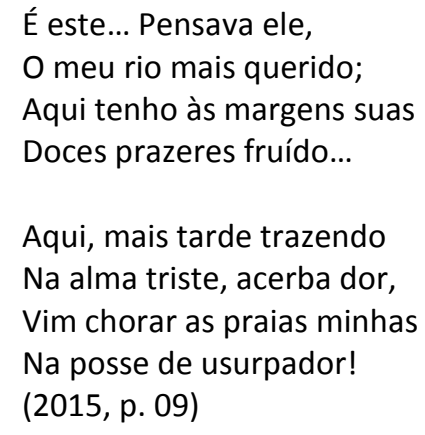

O Caeté, representando o choro da sua tribo diante das terras perdidas, lamenta as riquezas que foram tomadas, ou melhor, que passaram a ser denominadas a alguém, pois antes pertenciam a todos e após o processo de colonização/dominação, passaram a pertencer aos interesses apenas do homem branco. E todo esse processo, por razões óbvias, recorreu à violência, tal como se vê em:

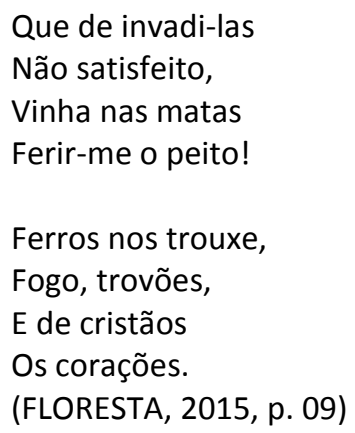

A leitura realizada acerca daquilo que, aparentemente, seria vantajoso para o indígena, pelo contrário, o tornou escravizado para atender aos comandos do europeu dominador. Conforme afirma Quijano "[...] raça e identidade racial foram estabelecidas como instrumentos de classificação social básica da população" (QUIJANO, 2005, p. 117). Assim, mudanças na identidade fundamentaram a relação de inferioridade entre conquistado e conquistador, que marca a era moderna na América. $\mathrm{E}$ esse processo se revela na voz do Caeté:

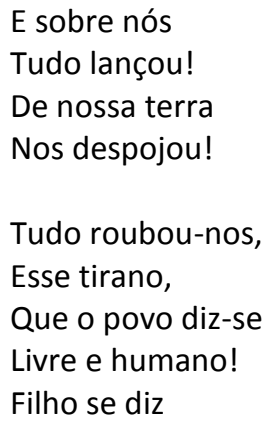


De Deus Potente

De quem profana

A obra ingente!

(FLORESTA, 2015, p. 10)

A discussão de Quijano engloba também as relações sociais e políticas da população excluída diante da condição de um processo de modernidade enraizado na colonização. Para ele, é urgente a decolonização no âmbito do controle das subjetividades, do conhecimento e das ideologias.

\section{Algumas construções no âmbito do literário}

Como foi possível constatar na secção anterior, Nísia Floresta dialoga com vários elementos do plano histórico, fazendo um arco desde o processo de aculturação indígena pelos portugueses à Revolução Praieira. Retomamos aqui brevemente esses contextos por compreender que, se normalmente História e Literatura não se separam, na obra A Lágrima de um Caeté tal cisão é ainda menos possível.

A retomada do elemento indígena nos é cara por dois motivos para além da reflexão histórica já destacada. No âmbito literário, podemos ressaltar como é forte a presença do que chamaríamos de 1a Geração Romântica, visto que Nísia nos traz a imagem de um Caeté forte, resistente às agruras e isso tende a configurar o mesmo ideário que teríamos, por exemplo, em Juca Pirama, indígena guerreiro que aparece na produção literária de Gonçalves Dias. Diferente deste, porém, temos na obra analisada uma espécie de Indianismo mesmo utópico e mais crítico. A construção romantizada fica apenas na esfera do maniqueísmo e do heroísmo, mas o Indianismo aqui é político, decolonial e visa à desconstrução da identidade nacional imposta pelo colonizador, ultrapassando o exotismo ufanista posterior de Gonçalves Dias e de tantos outros grandes nomes que sucederam o texto ora estudado.

O maniqueísmo nos é dileto pelo fato de o leitor poder distinguir, pela adesão da voz poética/narrador, o heroísmo direcionado ao nativo e, posteriormente, ao "descendente" politizado e revolucionário em oposição aos colonizadores portugueses, como é possível ser depreendido do seguinte aporte:

Era da natureza o filho altivo,

Tão simples como ela, nela achando Toda a sua riqueza, o seu bem todo... O bravo, o destemido, o grão selvagem, O Brasileiro era... - era um Caeté! (FLORESTA, 2015, p. 09)

Notemos, pois, que o Caeté tem uma imagem constituída de riquezas não só naturais por ser filho da terra como também as de um representante heroico como tínhamos na efígie de Vasco da Gama e na visibilidade do povo português em Os Lusíadas, de Camões ou em tantas outras construções 
épicas. Assim, no poema, há certa filiação a atos heroicos no poder do combate indígena e na dimensão coletiva que o Caeté simboliza.

Ainda sobre o fragmento destacado, podemos dizer que o uso do "Era na Natureza...", o tempo verbal no pretérito imperfeito já sugere uma digressão do que era o indígena livre no passado e, de certo modo, também nos indica como seria o herói vencido do presente. Dito de outro modo, o bom selvagem destemido à Rousseau não escapou aos grilhões da colonização, assim como, mais adiante no texto de Nísia Floresta, saberemos que o Praieiro revolucionário também não sobreviverá em matéria às animosidades dos conservadores Gabirus, restando-nos apenas a simbologia do herói tão bem representado na obra de Nísia.

Assim, não queremos dizer que a obra estudada segue o padrão épico, mas que possui certos elementos que remontam às epopeias. No mais, nem sequer a heroicidade se aparenta de forma tradicional, pois podemos afirmar que há dois heróis dignos da representatividade coletiva: o nativo derrotado pelo colonizador e o líder revolucionário, Nunes Machado, que mais que derrotado, acaba morto. No entanto, apesar de a Realidade endossar que o despotismo é cruel e mata a todos, também somos lembrados de que um herói "não morre em pensamento", pois ele "Pela Pátria viveu, deu tudo à Pátria, / A Pátria o cantará", afinal, o bravo guerreiro "para a Pátria não morrer" (FLORESTA, 2015, p. 27).

Para além dos feitos gloriosos do nativo como constructo de uma identidade coletiva e do ressaltar da natureza, ainda podemos salientar componentes primordiais das epopeias, como a existência de um plano histórico e um plano maravilhoso; e presença da dupla instância de enunciação.

A Lágrima de um Caeté é um texto lírico, narrativo e dramático ao mesmo tempo, ou seja, possui hibridação do discurso épico que, por sua vez, é claramente evidente no texto analisado e se encaixa de forma contundente no que Vasconcelos e Ramalho (2007) chamam de dupla instância, pois temos a manifestação tanto do gênero narrativo quanto do lírico e, por consequência, dispomos de um narrador que é também eu lírico; logo, "a especificidade do discurso épico não se define nem pela instância narrativa nem pela lírica" (VASCONCELOS e RAMALHO, 2007, p. 51), mas por essa dupla instância de enunciação.

Sobre o plano histórico, não mais nos debruçaremos por acreditar que ele fora explicitado na secção anterior, mas é da união desse plano com o maravilhoso que também as epopeias são erguidas e, nessa esfera, igualmente podemos trilhar os estudos da obra citada, pois há alegorias que remontam aos deuses da mitologia, uma vez que compreendemos a Liberdade e a Realidade como espécies de divindades que apontam para uma perspectiva evolutiva da sociedade de forma enigmática e misteriosa. Sobre isso, Ramalho salienta que: 
Compreender a importância do plano maravilhoso em uma epopeia constitui, de certo modo, um exercício de compreensão do próprio vínculo do ser humano com o mistério, com o desejo de "saber" e a sabedoria de aceitar a impossibilidade de "saber bem", dada não só a relatividade das coisas como a inserção do desconhecido como uma categoria real da vida (RAMALHO, 2017, p. 207).

As experiências entre a existência humana e o próprio indivíduo aparecem nas epopeias por meio de ninfas, deuses e tantos outros seres que compõem o mundo mítico, uma vez que é como se só pelo inexplicável pudéssemos compreender a nós mesmos. Dito de outro forma, é basilar para uma epopeia a fusão entre o plano histórico e o maravilhoso e isso, a priori, também é marcante na obra em análise, pois os ocorridos históricos são emaranhados de literariedade não só pela narrativa em versos, mas pelas vozes míticas da Realidade e da Liberdade, pois é a partir delas que tanto o indígena quanto o praieiro e, em especial o leitor, passam a compreender a dinâmica das experiências.

Não nos esqueçamos que, para Candido (1985), a dialética entre obra, história e seus pares, como a sociologia e a psicologia, devem confluir para um maior entendimento de qualquer texto literário, ou seja, em maior ou menor grau, no literário, sempre será proeminente o diálogo entre texto e contexto.

Ainda pensando nas possíveis pontes entre passado histórico e literário com a obra de Nísia Floresta, devemos salientar que há tanto as instâncias de contato já mencionados quanto as de afastamento. A propósito, diferente de uma elevação clássica, A Lágrima de Um Caeté pode ser chamada no máximo de uma epopeia moderna por não possuir certas convenções ditadas pela epopeia clássica e tão seguidas por muitos poetas. O poema tem um cunho narrativo e isso, embora ainda o ligue à epopeia, possui uma organização que se afasta da mesma, uma vez que há grande variação na estrutura dos versos e na metrificação.

Além disso, não acreditamos numa tentativa da autora em erguer utopicamente uma nação, pois o representante Caeté aparece triste às margens de um rio próximo a Recife e é ainda mais desiludido por uma voz personificada, via alegoria antropomorfizada, a abandonar suas esperanças e voltar à floresta. Sendo assim, o poema nos remete mais a uma elegia, pelo tom triste e, inclusive, já prenunciado pelo título, que a uma epopeia nos antigos moldes. Dito isso, não negamos nem afirmamos ser $A$ Lágrima de um Caeté uma epopeia, mas endossamos a provocação de chamar a obra de epopeia moderna ou até mesmo destacar a necessidade de uma nova nomenclatura e um novo volver de olhos dos estudos de teoria literária, que aqui não desenvolveremos por não ser nosso objetivo.

Aliás, a Realidade, o ente que guia o eu lírico/narrador, é um dos elementos mágicos que mostra toda inveja, cobiça e revolta que passam a existir no país depois da vinda do mal encarnado 
nos falsos descobridores, que representam o invasor estrangeiro, ou melhor, o opressor colonizador. Vejamos:

\author{
Ó terra de meus pais, ó Pátria minha! \\ Que seus restos guardando, viste de outros \\ Longo tempo a bravura disputar \\ Ao feroz estrangeiro a Pátria nossa, \\ A nossa liberdade, os frutos seus!... \\ Recolhe o pranto meu, quando dispersos \\ Pelas vastas florestas tristes vagam \\ Os poucos filhos teus à morte escapos, \\ Ao jugo de tiranos opressores, \\ Que em nome do piedoso céu vieram \\ Tirar-nos estes bens que o céu nos dera! \\ As esposas, a filha, a paz roubar-nos!... \\ Trazendo d'além-mar as leis, os vícios, \\ Nossas leis e costumes postergaram! \\ Por nossos costumes singelos e simples \\ Em troco nos deram a fraude, a mentira. \\ De bárbaros nos dando o nome, que deles \\ $\mathrm{Na}$ antiga e moderna História se tira. \\ (FLORESTA, 2015, p. 10-11)
}

Logo, o Caeté olha, nostálgico, para as praias usurpadas pelo estrangeiro assim como compreende todos os males trazidos pelo outro, mas isso não ocorre despropositada e aleatoriamente. A voz da razão ou mesmo o subconsciente do triste Caeté tem sempre o despertar pela sensatez da Realidade, que constantemente atordoa o herói com seu tom de verdade que reforça a visão de que ele é um oprimido em sua própria terra, pois não carregará em si sequer a metáfora da mãe que morre para dar vida ao seu filho e simbolizar uma nova nação, como temos em Iracema, de José de Alencar. Ao Caeté, resta o que diz a Realidade e a dúvida sobre si, sobre a deidade e sobre o futuro, ficando atordoado, como podemos concluir no seguinte fragmento:

O bravo selvagem atônito ficou...

- Quem és, lhe pergunta, infernal deidade?

- Uma visão de inferno não sou:

Sou cá deste mundo a Realidade.

Volta às selvas tuas, vai lá procurar

Alguns desses bens, que aqui te hão tirado:

Não creias, ó mísero, jamais encontrar

A paz, a ventura que aqui tens gozado.

(FLORESTA, 2015, p. 32)

Essa voz da Realidade sempre mostra ao bravo selvagem que ele nunca terá paz, mas a alegoria tem o seu duplo, uma vez que há outra também feminina, mas em visão e postura oposta, a Esperança. Tomemos as suas representações em analogia aos deuses que guiavam os heróis em seus feitos grandiosos, mas que, aqui, nos serve como voz da consciência. 
Antes de volvermos nosso olhar mais detalhadamente à entidade Esperança, devemos pensar em como é dividido o texto de Nísia, segundo Margutti (2019). Para ele, o poema é dividido em cinco partes. Na primeira, o leitor é apresentado ao cenário e ao indígena Caeté, "sob a forma de um vulto que passeia às margens do rio Beberibe, recordando um passado doloroso em que foi desalojado de suas terras pelo despotismo" (MARGUTTI, 2019, p. 36); na segunda, temos a perda da terra pelo nativo e a substituição de suas tradições pelas imposições e dominações dos conquistadores; na terceira, passamos a vislumbrar as "tropas rebeldes avançando e anunciando a libertação da terra dos caetés pelo herói Nunes Machado, descendente e vingador tanto desses índios como dos mortos nas revoluções de 1817 e 1824 em Recife" (MARGUTTI, 2019, p. 36), mas não nos esqueçamos de que Nunes Machado morre, o que acaba provocando ainda mais dor e lamento; na quarta parte, por sua vez, podemos destacar o tom de homem morto elevado a herói eterno, uma vez que sua memória ficará viva para sempre para dar energia aos próximos guerreiros do país e assim se solidifica ainda mais a construção de um herói sem vitórias, porém, símbolo de esperança para outrora.

A quinta parte merece maior destaque por ser a que adentraremos no maravilhoso e retomaremos às alegorias da Realidade e da Liberdade. Nesse âmbito, Margutti endossa que:

Na quinta e última parte (estrofes CVIII-CXLI, versos 564-712), o Caeté dialoga com as figuras alegóricas da Realidade e da Liberdade. A primeira argumenta que ele deve voltar à floresta, porque os brasileiros estão completamente indiferentes ao destino dos índios. A segunda desce dos céus sob a forma de uma bela virgem que atrai o Caeté. A Realidade revela a ele que a virgem é a Liberdade e que o monstro a ser enfrentado é o Despotismo. E acrescenta que, por mais que o Caeté tente, nunca poderá alcançar a Liberdade. Por desígnio divino, o Despotismo será expulso do Brasil no futuro, mas a melhor opção para o Caeté continua sendo refugiar-se na floresta. MARGUTTI, 2019, p. 36)

Sendo assim, pelo plano literário, podemos perceber os planos histórico e maravilhoso, pois o Despotismo que se enraizava já naquela época é descortinado pela alegoria da Liberdade, que aparece como uma bela e sedutora musa que quer conduzir o Caeté à vingança.

\footnotetext{
Tudo podes tu fazer,

Menos descer

Às trevas do esquecimento

Os mártires da Liberdade,

A Divindade

Lhes tem marcado o momento.

(FLORESTA, 2015, p. 26)
}

Já aqui vemos que a Liberdade o seduz com a ideia de que tudo um herói pode fazer. Em versos mais adiante, nitidamente, aparece o indígena ainda mais absorto em admiração à Liberdade; no entanto, junto a essa imagem, passamos a ter outros seres ao redor, como "fúrias cantando, / Em funéreo coro a morte [...]" (FLORESTA, 2015, p. 35) e, mesmo assim, o encantamento do Caeté pela Liberdade apenas cresce, como notamos nos versos seguintes: 


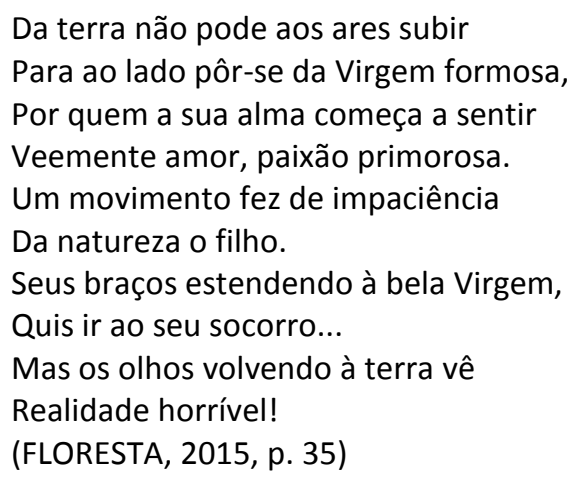

Em vista disso, o Caeté assimila que é tão impossível ter a Liberdade perto de si quanto vencer os cruéis invasores, pois a Realidade é implacável e, para desespero seu, deixa ainda mais nítido que seu rumo deve ser a floresta e não resistir ao que não pode enfrentar:

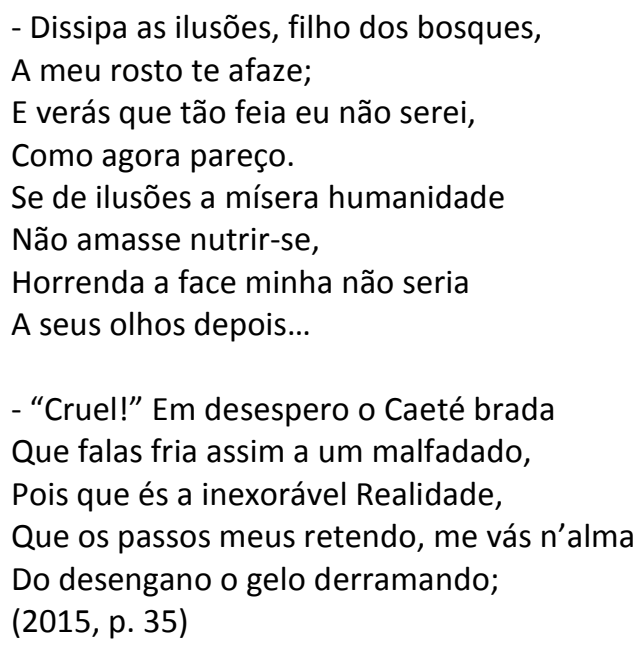

O diálogo entre Realidade e Caeté faz com que leitor e herói também se justaponham para dissipar as ilusões de que é possível trazer a Liberdade a um mundo tão caótico e mesquinho, pois a Realidade apelativamente reverbera uma verdade dolorida de que se todos fossem como Nunes Machado, só nos sobraria a dor pelos heróis mortos. Então, para sua sobrevivência, o Caeté deve voltar a perambular às margens, agora do Rio Goiana, para expandir suas dores e ecoar o nome imortal do herói de sua Pátria, ou seja, Liberdade e Realidade são alegorias para se pensar criticamente sobre todas as ambiguidades inerentes à construção da Identidade de um país aculturado.

Assim, devemos concluir a secção a nos questionar: quem são nossos heróis e nossos mitos? Apenas seres miraculosos e inexistentes ou uma força consciente que pode existir em cada indivíduo e gesto, para além das lágrimas nos nossos primeiros nativos. 


\section{Considerações finais}

Notadamente, tivemos, em A Lágrima de Um Caeté, a possibilidade de um estudo que se moveu entre o histórico e o literário; o épico e o moderno; e, inclusive, entre o herói coletivo e o indivíduo verossímil com imperfeições.

Considerando os aspectos trabalhados, foi possível revisitarmos a linha histórica entre a Revolução Praieira, as transformações sociais e a atualidade, destacando os estudos acerca da condição do sujeito frente às consequências do poder eurocêntrico, e, assim, deparamo-nos com um texto do século XIX que já apontava para a necessidade dos estudos decoloniais.

Na linha literária, a autora nos permitiu verificar a possibilidade de diálogo presente no gênero épico com a modernidade, não se fixando em estruturas, fazendo uso do maravilhoso para a construção de críticas pontuais, podendo perpetuar, no texto, a memória aos grandes líderes em defesa da justiça, da terra e da identidade de um povo assim como de uma cultura.

Ao término desta breve pesquisa, porém, ficamos com a sensação de que a obra de Nísia Floresta tem muito ainda a ser desbravada e que requer um olhar mais inquiridor e aprofundado. Afinal, nosso intento fora apenas trilhar certos caminhos em torno de alguns elementos históricos e literários, mais em nível de provocação.

\section{Referências bibliográficas}

CANDIDO, Antonio. Literatura e Sociedade. São Paulo: Companhia Editora Nacional, 1985.

CARVALHO, Marcus Joaquim Maciel. Os nomes da Revolução: lideranças populares na Insurreição Praieira, Recife, 1848-1849. In. Revista Brasileira de História, UFPE, Jul, 2003. Disponível em: https://doi.org/10.1590/S0102-01882003000100009. Acesso em: 06 jun. 2021.

DUARTE, Constância Lima. Revendo o indianismo brasileiro: A Lágrima de um Caeté, de Nísia Floresta. UFMG, 1999. Disponível em: http://www.letras.ufmg.br/cesp/textos/(1999)06revendo.pdf. Acesso em: 25 abril. 2021.

MARGUTTI, Paulo Nísia Floresta, uma brasileira desconhecida: feminismo, positivismo e outras tendências. Porto Alegre: Editora Fi, 2019.

PEREIRA, Waldemar Valença. A lágrima de um caeté, de Nísia Floresta, como corpus sensível e possível para o $9^{\circ}$ ano. 2015. 149 f. Dissertação (Mestrado em Letras) - Universidade Federal de Sergipe, UFS, Itabaiana, SE, 2015.

QUIJANO, Aníbal. Colonialidade do poder, eurocentrismo e América Latina. In: Colonialidade do saber: eurocentrismo e ciências sociais. Buenos Aires: Clacso, 2005.

RAMALHO, Christina. A cabeça calva de Deus, de Corsino Fortes: o epos de uma nação solar no cosmos da épica universal. Aracaju: ArtNer, 2017.

VASCONCELOS DA SILVA, Anazildo; RAMALHO, Christina. História da Epopéia Brasileira: Teoria, Crítica e Percurso. Rio de Janeiro: Garamond, 2007. 